\title{
Optimization of Process Parameters of Laser Cladding 304L Alloy Powder Based on Orthogonal Experiment
}

\author{
Linsen SHU ${ }^{12 \star}$, Bo WANG ${ }^{1}$, Yayin $\mathrm{HE}^{1}$ \\ 1 School of Mechanical Engineering, Shaanxi University of technology, Hanzhong, Shaanxi, China \\ 2 Shaanxi Key Laboratory of Industrial Automation, Hanzhong, Shaanxi, China
}

*Corresponding Author: Linsen SHU, School of Mechanical Engineering, Shaanxi University of technology, Hanzhong, Shaanxi, 723001, China

\begin{abstract}
:
In order to find the optimal combination of process parameters for laser cladding 304L alloy powder on the surface of 45 steel, a combination method of single factor test and multi-factor orthogonal experiment was used to perform the single pulse laser cladding experiment. The effects of process parameters (pulse current A, pulse width B, pulse frequency C,defocus distance D, scan velocity E) on the morphology and performance of cladding layer was studied by range analysis, and the optimal combination of cladding parameters is calculated by fuzzy comprehensive evaluation. The results show that different process parameters have different effects on the morphology of the cladding layer and scanning velocity $\mathrm{E}$ and defocus distance $\mathrm{D}$ are the most important influencing factor of cladding morphology. The effect on cladding width is $\mathrm{D}>\mathrm{C}>\mathrm{A}>\mathrm{B}>\mathrm{E}$ and the effect on cladding height is $\mathrm{E}>\mathrm{A}>\mathrm{C}>\mathrm{D}>\mathrm{B}$. The optimal combination of cladding width is $\mathrm{A}_{4} \mathrm{~B}_{4} \mathrm{C}_{4} \mathrm{D}_{4} \mathrm{E}_{2}$. The optimal combination of cladding high is $\mathrm{A}_{2} \mathrm{~B}_{1} \mathrm{C}_{1} \mathrm{D}_{4} \mathrm{E}_{1}$. The comprehensive optimal process parameters are pulse current $210 \mathrm{~A}$, pulse width $3.6 \mathrm{~ms}$, pulse frequency $16 \mathrm{~Hz}$, defocus distance $+10 \mathrm{~mm}$ and scanning speed $240 \mathrm{~mm} / \mathrm{min}$. The average hardness of the cladding layer, melting pool, heat-affected zone and substrate under the optimal process parameters is $406.2 \mathrm{HV}_{0.5}, 470.8 \mathrm{HV}_{0.5}, 230.5 \mathrm{HV}_{0.5}$ and $202.0 \mathrm{HV}_{0.5}$, respectively. The $304 \mathrm{~L}$ cladding layer on 45 steel surface is stable in width, height and surface quality under comprehensive optimal parameters.

Keywords: laser optical; the optimal process; orthogonal test; 304L alloy powder; laser cladding; fuzzy comprehensive evaluation.
\end{abstract}

\section{Introduction}

Laser cladding is a coating technology that deposits multiple layers of composite material on the substrate to improve the physical properties of the work-piece such as wear resistance and corrosion resistance ${ }^{[1-4]}$. Laser cladding technology is widely used in surface enhancement and wear repair of parts ${ }^{[5-9]}$. Laser cladding technology has good adaptability and no special requirements for metal powder and substrate. It can obtain high performance alloy on cheap and low performance metal surface and can significantly improve the mechanical properties of mechanical parts ${ }^{[10-11]}$.Steel 45 is a common material used in manufacturing machine parts. It has important industrial application value to prepare wear - resistant and corrosion - resistant cladding layer with high hardness on the surface of 45 steel.

At present, the research of preparing high performance alloy cladding layer on low performance metal has been published. Parekh $\mathrm{R}$ et al. ${ }^{[12]}$ studied the optimization of cladding forming geometry and found that laser cladding process parameters had a direct impact on its geometry. Jiao X.Yet al. ${ }^{[13]}$ studied the influence of scanning velocity on the microstructure of cladding layer, and found that increasing velocity would induce defects.Lei J.F et al. ${ }^{[14]}$ studied the laser cladding Ni60-25\% WC coating on U71Mn steel surface and obtained the optimal process parameters. ZanS.P et al. ${ }^{[15]}$ studied the laser cladding technology of 316L stainless steel powder, and analyzed the effect of technological parameters on surface morphology and hardness.Xu M.S et al. ${ }^{[16]}$ studied the microstructure and properties of laser cladding $\mathrm{Ni}$ base alloy of 45 steel. $\mathrm{Xu}$ Q.K et al. ${ }^{[17]}$ studied the technicality of TiBCN powder $\mathrm{CO}_{2}$ laser cladding on the surface of steel 45.Liu X.M et al. ${ }^{[18]}$ studied 45 steel laser cladding Ni35B+WC alloy and found that WC content can improve the hardness and wear resistance of cladding layer. The above studies show that the process parameters are the main factors affecting the morphology, microstructure, hardness distribution and wear resistance of the coating.However, there is little 
literature on the cladding layer of 304L alloy on the surface of 45 steel by pulsed laser, and there is a lack of optimized process parameters. As a result, the $304 \mathrm{~L}$ alloy powder is not widely used in remanufacturing and surface strengthening of mechanical parts.

In this paper, the process optimization of laser cladding 304L alloy powder on 45 steel surface is studied.Firstly, single-factor test and multi-factor orthogonal test are carried out to analyze the influence of each process factor on the morphology of single-pass cladding layer.Then the range analysis method is used to evaluate the significant order of the influence of each process parameter on the single-pass cladding morphology.Based on the orthogonal test results, multi-objective fuzzy comprehensive evaluation is carried out to find the comprehensive optimal combination of cladding process parameters. Finally, the stability of the synthetic optimal process is verified by the test of morphology and hardness ${ }^{[19-21]}$.

\section{Orthogonal Experimental Design}

\subsection{Experimental equipment and materials}
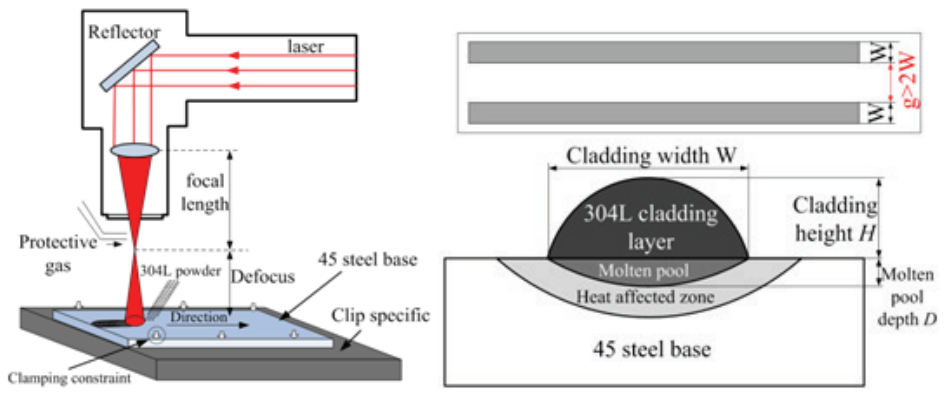

Figure 1. Schematic diagram of experimental principle of Laser cladding.

Table 1. Chemical composition of 304L stainless steel alloy powder and 45 steel substrate (wt\%).

\begin{tabular}{ccccccccccc}
\hline Materials & $\mathrm{C}$ & $\mathrm{Si}$ & $\mathrm{Mn}$ & $\mathrm{Ni}$ & $\mathrm{Cr}$ & $\mathrm{P}$ & $\mathrm{S}$ & $\mathrm{Cu}$ & $\mathrm{O}$ & $\mathrm{Fe}$ \\
\hline 304L alloy powder & $\leq 0.03$ & $\leq 1.0$ & $\leq 0.2$ & $8.0-12.0$ & $18.0-20.0$ & - & - & - & $\leq 0.15$ & $\mathrm{Bal}$ \\
45 steel & 0.45 & 0.20 & 0.20 & $\leq 0.25$ & $\leq 0.25$ & $\leq 0.035$ & $\leq 0.035$ & $\leq 0.25$ & - & $\mathrm{Bal}$ \\
\hline
\end{tabular}

\subsection{Design of experimental scheme}

Due to the laser cladding machine used has many technological parameters and each parameter can be adjusted widely, the orthogonal experiment of multiple factors was carried out. The orthogonal experiment scheme $L_{16}\left(4^{5}\right)$ was designed, as shown in Table 2 .

The macroscopic morphologies of 16 groups of singlepass cladding layers were obtained by orthogonal test, as
The Nd: YAG pulse laser cladding machine with a power of 800 watts is used in the experiment.The effective range of the cladding process parameters of the equipment: pulse current is $200 \mathrm{~A} \sim 230 \mathrm{~A}$, pulse width is $3.0 \mathrm{~ms}$ $\sim 3.6 \mathrm{~ms}$, frequency is $14 \mathrm{~Hz} \sim 17 \mathrm{~Hz}$, defocusing amount is $+8 \mathrm{~mm} \sim+14 \mathrm{~mm}$, and scanning speed is $240 \mathrm{~mm} / \mathrm{min}$ $\sim 330 \mathrm{~mm} / \mathrm{min}$.In order to avoid mutual influence of each channel of cladding and interference of residual heat of substrate, laser beams were scanned along the same direction during the test. The spacing g between adjacent cladding strips was set to be more than 2 times of the width $\mathrm{W}$ of single channel of cladding, and the scanning cooling interval was set to be 10 minutes. The experimental principle was shown in Figure 1.

The particle size of 304L stainless steel alloy powder is 180-320 mesh, the loose packing density is $3.8 \mathrm{~g} /$ $\mathrm{cm}^{3}$, the base material is the 45 steel plate after being polished and cleaned, the length, width and height is $200 \mathrm{~mm} \times 80 \mathrm{~mm} \times 10 \mathrm{~mm}$. The mass fraction of $304 \mathrm{~L}$ stainless steel alloy powder and 45 steel composition is shown in Table 1.

Table 2. Multi-factor orthogonal experimental scheme $\left(L_{16}\left(4^{5}\right)\right)$.

\begin{tabular}{cccccccc}
\hline \multirow{2}{*}{ Number } & $\begin{array}{c}\text { Pulse current } \\
\text { A }\end{array}$ & $\begin{array}{c}\text { Pulse width } \\
\mathrm{ms}\end{array}$ & $\begin{array}{c}\text { Pulse frequency } \\
\mathrm{Hz}\end{array}$ & $\begin{array}{c}\text { Defocus distance } \\
\mathrm{mm}\end{array}$ & $\begin{array}{c}\text { Scan velocity } \\
\mathrm{mm} \cdot \mathrm{min}^{-1}\end{array}$ & $\begin{array}{c}\text { Layer width } \\
\mathrm{mm}\end{array}$ & $\begin{array}{c}\text { Layer height } \\
\mathrm{mm}\end{array}$ \\
\hline 1 & 200 & 3.0 & 14 & +8 & 240 & 1.80 & 0.52 \\
2 & 200 & 3.2 & 15 & +10 & 270 & 2.12 & 0.38 \\
3 & 200 & 3.4 & 16 & +12 & 300 & 2.60 & 0.32 \\
\hline
\end{tabular}




\begin{tabular}{cccccccc}
\hline Number & $\begin{array}{c}\text { Pulse current } \\
\text { A }\end{array}$ & $\begin{array}{c}\text { Pulse width } \\
\mathrm{ms}\end{array}$ & $\begin{array}{c}\text { Pulse frequency } \\
\mathrm{Hz}\end{array}$ & $\begin{array}{c}\text { Defocus distance } \\
\mathrm{mm}\end{array}$ & $\begin{array}{c}\text { Scan velocity } \\
\mathrm{mm} \cdot \mathrm{min}^{-1}\end{array}$ & $\begin{array}{c}\text { Layer width } \\
\mathrm{mm}\end{array}$ & $\begin{array}{c}\text { Layer height } \\
\mathrm{mm}\end{array}$ \\
\hline 4 & 200 & 3.6 & 17 & +14 & 330 & 3.06 & 0.30 \\
5 & 210 & 3.2 & 14 & +14 & 300 & 2.32 & 0.58 \\
6 & 210 & 3.0 & 15 & +12 & 330 & 2.48 & 0.38 \\
7 & 210 & 3.6 & 16 & +10 & 240 & 2.66 & 0.54 \\
8 & 210 & 3.4 & 17 & +8 & 270 & 2.54 & 0.40 \\
9 & 220 & 3.4 & 14 & +10 & 330 & 2.36 & 0.32 \\
10 & 220 & 3.6 & 15 & +8 & 300 & 2.58 & 0.30 \\
11 & 220 & 3.0 & 16 & +14 & 270 & 2.92 & 0.56 \\
12 & 220 & 3.2 & 17 & +12 & 240 & 2.80 & 0.42 \\
13 & 230 & 3.6 & 14 & +12 & 270 & 2.86 & 0.38 \\
14 & 230 & 3.4 & 15 & +14 & 240 & 2.98 & 0.44 \\
15 & 230 & 3.2 & 16 & +8 & 330 & 2.54 & 0.30 \\
16 & 230 & 3.0 & 17 & +10 & 300 & 2.72 & 0.30 \\
\hline
\end{tabular}

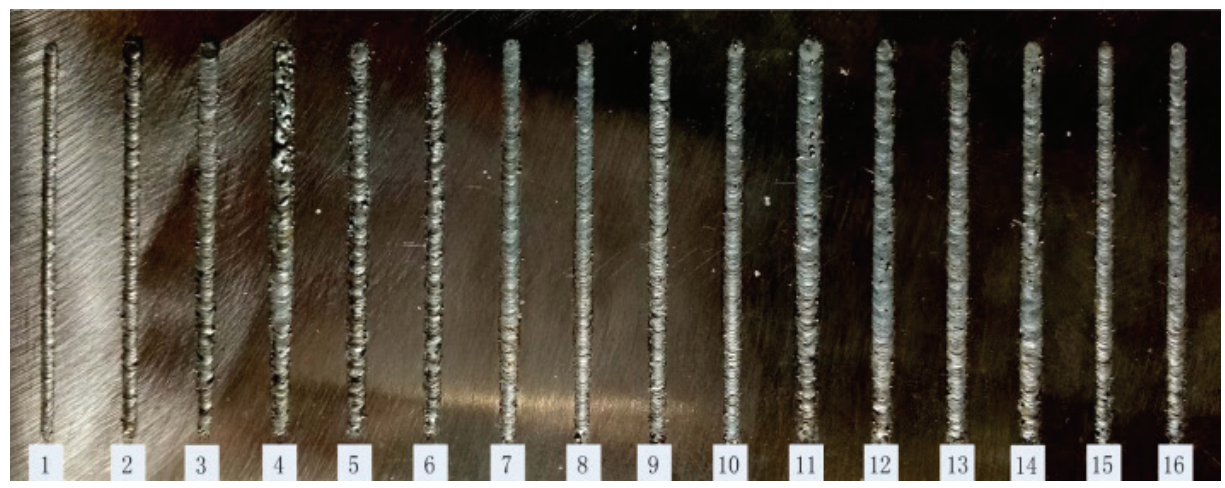

Figure 2. Multi-factor orthogonal experimental results.

\section{Results and Discussion}

\subsection{Section morphology analysis}

The cladding layer was cut along the direction perpendicular to the cladding, the cross section of cladding layer was observed by optical microscope, and the cross-section morphologies of 16 groups of samples were obtained, as
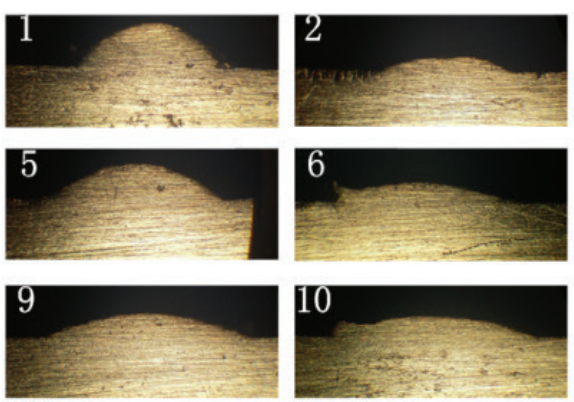

13
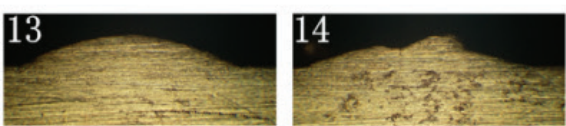

shown in Figure 3. As it can be seen from the figure, No. 1 cladding layer is height and narrow; No. 4, 9, 15 and 16 cladding layers are relatively flat, and the height and width do not meet the cladding requirements;No. 2, 6, 10 and 14 cladding layers are unevenly distributed and convex, and the cladding layer is not well fused;The surface of No. 3, $5,7,8,11,12$ and 13 cladding layers is flat and has better height and width.
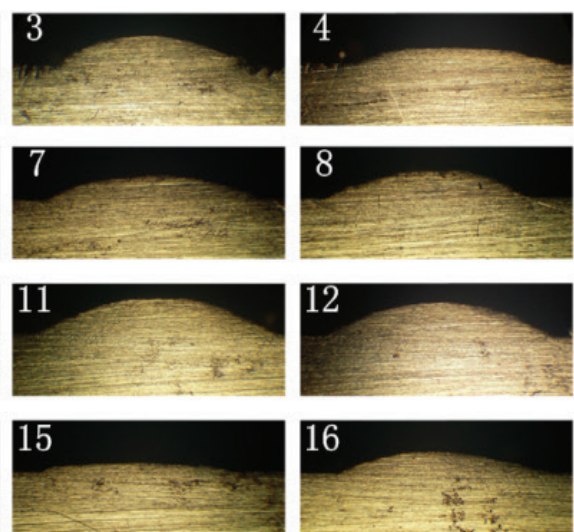

Figure 3. Cross-section microscopic image of a single laser cladding layer in orthogonal test. 


\subsection{Range analysis}

Set $T_{i j}$ be the sum of experimental results $y_{m}\left(y_{1}\right.$ and $y_{2}$ are the width and height of cladding layer, respectively) at the level $j$ in column $i$. $K_{i j}$ is the experimental mean value at the $j$-th level of column $i$. $R$ is the range value of column $i$, indicating the range of variation of the test index within the value range of this factor. $\operatorname{Max}(K)$ and $\min (K)$ are the maximum and minimum $K$ values in column $i$ respectively. In formula (1), $j$ is the number of levels, $i$ is the number of columns, namely the number of factors (A, B, C, D, E), and $r$ is the number of repeated tests at the same level in a certain factor.

$$
\left\{\begin{array}{l}
T_{i j}=\sum_{j=1}^{4} y_{m} \\
K_{j}=\frac{T_{j}}{r} \\
R=\max (K)-\min (K)
\end{array}\right.
$$

The range analysis can determine the primary and secondary factors that affect the experimental results. The large range indicates that the factor has a great influence on the experimental results, and it is the main factor.The small range indicates that this factor has a great influence on the experimental results, and it is a secondary factor.

The width and height of the cladding layer are measured by the microhardness tester, and the range analysis results of laser cladding test results are calculated by using formula (1), as shown in Table 3. It can be seen from the Table 4 that the main factor affecting the cladding layer width is scanning speed $\mathrm{E}$, and the corresponding optimal combination is $\mathrm{A}_{4} \mathrm{~B}_{4} \mathrm{C}_{4} \mathrm{D}_{4} \mathrm{E}_{2}$. The main factor affecting the cladding layer height is also the scanning speed $\mathrm{E}$, whose optimal combination is $\mathrm{A}_{2} \mathrm{~B}_{1} \mathrm{C}_{1} \mathrm{D}_{4} \mathrm{E}_{1}$. The effect of scanning speed on height and width of the cladding layer is the main factor, the focal length has a greater effect on the width of the cladding layer and the least effect on the height, and the effect of pulse width and frequency on the height and

\begin{tabular}{|c|c|c|c|c|c|c|}
\hline Items & & $\begin{array}{c}\text { Pulse } \\
\text { current } \\
\text { Factor A }\end{array}$ & $\begin{array}{l}\text { Pulse width } \\
\text { Factor B }\end{array}$ & $\begin{array}{c}\text { Pulse frequency } \\
\text { Factor C }\end{array}$ & $\begin{array}{l}\text { Defocus } \\
\text { distance } \\
\text { Factor D }\end{array}$ & $\begin{array}{c}\text { Scan velocity } \\
\text { Factor E }\end{array}$ \\
\hline \multirow{12}{*}{$\begin{array}{c}\text { The width of } \\
\text { the cladding } \\
\text { layer } \\
\text { mm }\end{array}$} & $T_{i 1}$ & 9.58 & 9.92 & 9.34 & 9.46 & 10.24 \\
\hline & $T_{i 2}$ & 10.00 & 9.78 & 10.16 & 9.86 & 10.44 \\
\hline & $T_{i 3}$ & 10.66 & 10.48 & 10.72 & 10.74 & 10.22 \\
\hline & $T_{i 4}$ & 11.10 & 11.16 & 11.12 & 11.28 & 10.44 \\
\hline & $K_{i 1}$ & 2.40 & 2.48 & 2.34 & 2.36 & 2.56 \\
\hline & $K_{i 2}$ & 2.50 & 2.45 & 2.54 & 2.47 & 2.61 \\
\hline & $K_{i 3}$ & 2.67 & 2.62 & 2.68 & 2.69 & 2.55 \\
\hline & $K_{i 4}$ & 2.78 & 2.79 & 2.78 & 2.82 & 2.61 \\
\hline & $R$ & 0.38 & 0.35 & 0.45 & 0.46 & 0.06 \\
\hline & \multicolumn{5}{|c|}{ The precedence order of the factors: $D>C>A>B>E$} & \multirow{3}{*}{$\mathrm{E}_{2}$} \\
\hline & Optimization levels & $\mathrm{A}_{4}$ & $\mathrm{~B}_{4}$ & $\mathrm{C}_{4}$ & $\mathrm{D}_{4}$ & \\
\hline & Optimal combination & & & $\mathrm{A}_{4} \mathrm{~B}_{4} \mathrm{C}_{4} \mathrm{D}_{4} \mathrm{E}_{2}$ & & \\
\hline \multirow{12}{*}{$\begin{array}{l}\text { The high of } \\
\text { the cladding } \\
\text { layer } \\
\text { mm }\end{array}$} & $T_{i 1}$ & 1.52 & 1.76 & 1.80 & 1.52 & 1.92 \\
\hline & $T_{i 2}$ & 1.90 & 1.68 & 1.50 & 1.54 & 1.72 \\
\hline & $T_{i 3}$ & 1.60 & 1.48 & 1.72 & 1.50 & 1.50 \\
\hline & $T_{i 4}$ & 1.42 & 1.52 & 1.42 & 1.88 & 1.30 \\
\hline & $K_{i 1}$ & 0.38 & 0.44 & 0.45 & 0.38 & 0.48 \\
\hline & $K_{i 2}$ & 0.48 & 0.42 & 0.37 & 0.39 & 0.43 \\
\hline & $K_{i 3}$ & 0.40 & 0.37 & 0.43 & 0.38 & 0.38 \\
\hline & $K_{i 4}$ & 0.36 & 0.38 & 0.35 & 0.47 & 0.32 \\
\hline & $R$ & 0.12 & 0.07 & 0.10 & 0.09 & 0.16 \\
\hline & \multicolumn{6}{|c|}{ The precedence order of the factors: $\mathrm{E}>\mathrm{A}>\mathrm{C}>\mathrm{D}>\mathrm{B}$} \\
\hline & Optimization levels & $\mathrm{A}_{2}$ & $\mathrm{~B}_{1}$ & $\mathrm{C}_{1}$ & $\mathrm{D}_{4}$ & $\mathrm{E}_{1}$ \\
\hline & Optimal combination & & & $\mathrm{A}_{2} \mathrm{~B}_{1} \mathrm{C}_{1} \mathrm{D}_{4} \mathrm{E}_{1}$ & & \\
\hline
\end{tabular}
aspect ratio of the cladding layer is in the middle level.

Table 3. Range analysis. 
Range analysis cannot directly reflect the optimal results under the control of multiple indexes, and comprehensive evaluation is needed to determine the comprehensive optimal process parameter combination. Therefore, the surface height and width indexes of $304 \mathrm{~L}$ laser cladding layer are comprehensively analyzed by fuzzy comprehensive evaluation method.

The specific methods of comprehensive analysis are:

Firstly, the fuzzy judgment matrix is obtained through the comment set of each sample factor set, and the weight judgment matrix of each evaluation index is obtained through expert knowledge and experience.

Then, the analytic hierarchy process (AHP) is used to analyze the weight consistency index and find the objective weight coefficient of each evaluation index.

Finally, fuzzy operator is used for fuzzy comprehensive evaluation.
The fuzzy comprehensive evaluation factor set: \{cladding height, cladding width\}, comment set: \{good, relatively good, general, bad, poor\}.The evaluation of cladding height $\widetilde{H}_{i}$ and cladding width $\widetilde{W}_{i}$ obtained the fuzzy matrix $\widetilde{F}_{i}(i=1,2,3 \ldots 16$, Where $i$ is the serial number of cladding strip), the first row of the matrix $\widetilde{F}_{i}$ values from $\widetilde{H}_{i}$, and the second row values from $\widetilde{W}_{i}$.

The zadeh operator is used to conduct compound operation on the fuzzy matrix to get the evaluation result $\widetilde{Z}_{i}$ , and the normalized processing is done $\widetilde{Z}^{*}{ }_{i}(i=1,2,3 \ldots 16)$, as shown in Table 4 . As can be seen from Table $4, \widetilde{Z}^{*}{ }_{7}$ and $\widetilde{Z}^{*}{ }_{8}$ should be the highest level, from the level of "good" quality, the comprehensive optimal result is $\widetilde{Z}^{*}{ }_{7}$. In other words, the comprehensive optimal process parameters are current $210 \mathrm{~A}$, pulse width $3.6 \mathrm{~ms}$, frequency $16 \mathrm{~Hz}$, defocusing amount $+10 \mathrm{~mm}$, and scanning speed $240 \mathrm{~mm} / \mathrm{min}$.

Table 4. Evaluation results of fuzzy matrix.

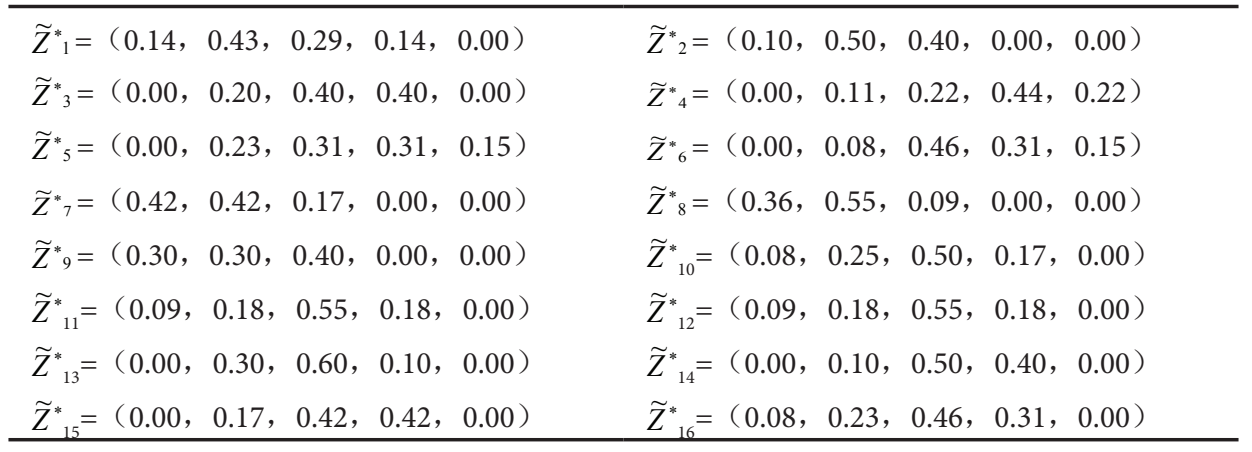

\subsection{Hardness testing}

Through the results of fuzzy comprehensive evaluation, it can be found that when the scanning speed and defocus are controlled in the range of $240 \sim 270 \mathrm{~mm} / \mathrm{min}$ and $+8 \sim$ $10 \mathrm{~mm}$ respectively, the cladding layer with better surface shape and no crack defects can be formed. Figure 4 (a) shows the three single-pass cladding morphologies under the optimal process parameters.It can be seen from the Figure 4 (a) that the surface of the cladding layer (No. 1, No. 2 and No. 3 ) is smooth and continuous, with uniform height and width, and good formation. The cladding width is $2.54 \mathrm{~mm}, 2.56 \mathrm{~mm}$ and $2.54 \mathrm{~mm}$, and the height is $0.56 \mathrm{~mm}, 0.54 \mathrm{~mm}$ and $0.54 \mathrm{~mm}$, respectively. Figure 4 (b) shows the cross section morphology of the cladding layer corroded by $4 \%$ nitric acid alcohol in No. 1 . It can be seen that the cladding layer has a good bond with the substrate, and no cracks, pores and other defects are found.

The micro-hardness of the No. 1 cladding sample in Fig. $4 \mathrm{~b}$ was observed, and 11 measuring points were set along the vertical direction on the section. The measuring point distribution in the cladding layer I molten pool II, IV,III heat-affected zone and the 45 steel base IV, respectively(as shown in Figure 5 (a). HV-1000 micro-hardness tester was used to measure the hardness of cladding samples (KGF $=0.5$ ), and the test results were shown in Figure 5 (b). By the figure shows, molten pool II has the highest hardness and as depth increases, the hardness of cladding layer I value is higher, but lower than the molten pool II matrix
IV minimum hardness, the hardness of heat affected zone III hardness value rapid transition from high to low hardness value, the final hardness is only slightly higher than the base material.Cladding layer I , molten pool II, heat affected zone III and IV average hardness are 406.2 $\mathrm{HV}_{0.5}, 470.8 \mathrm{HV}_{0.5}, 230.5 \mathrm{HV}_{0.5}, 202.0 \mathrm{HV}_{0.5}$, respectively. The average hardness of the cladding layer $\mathrm{I}$ is 2.33 times of the 45 steel substrate IV.

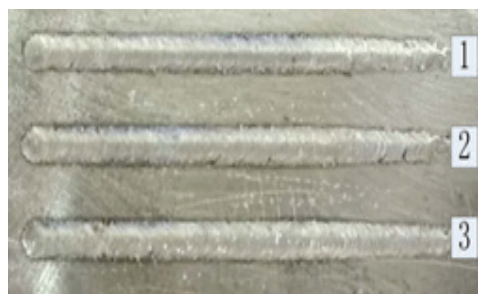

(a)morphology

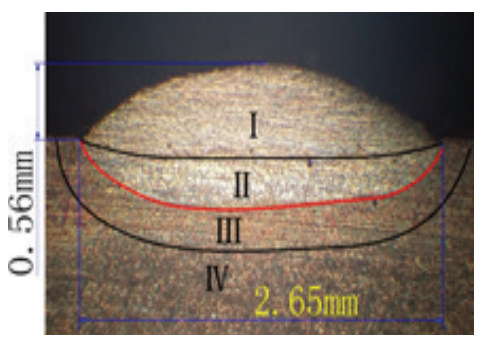

(b)the cross section shape.

Figure 4: Three single-pass cladding morphologies under the optimal process parameters 

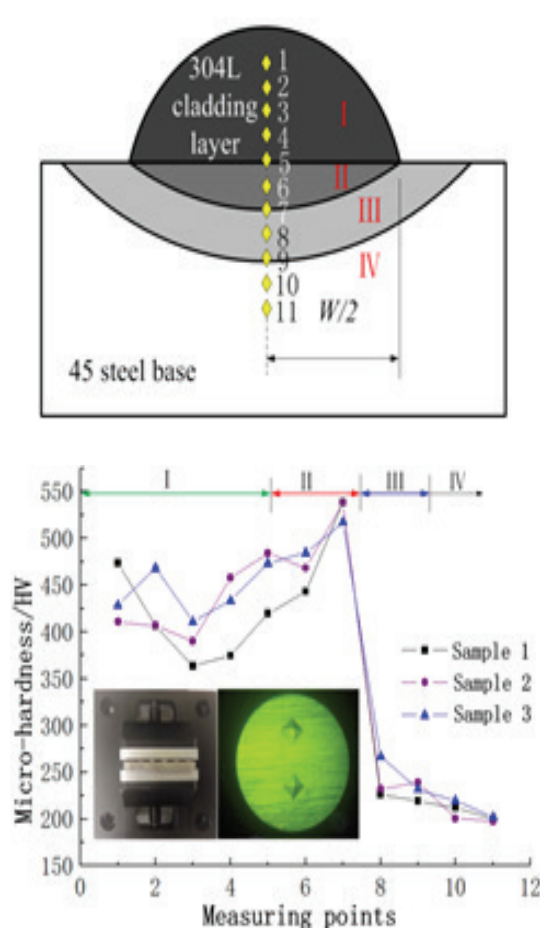

Figure 5. The micro-hardness of the cladding sample (a) position of measuring points;(b)hardness distribution curves.

\section{Conclusions}

The influence degree of different process parameters on the cladding layer morphology is found by range analysis of orthogonal test results. From the effect on cladding width, defocus distance $\mathrm{D}>$ frequency $\mathrm{C}>$ current $\mathrm{A}>$ pulse width B > scanning speed E. From the effect on cladding height, scanning speed $\mathrm{E}>$ current $\mathrm{A}>$ frequency $\mathrm{C}>$ defocus distance $\mathrm{D}>$ pulse width $\mathrm{B}$. The scanning velocity $\mathrm{E}$ and defocus distance Dare the most important factor affecting the cladding layer morphology.

The comprehensive optimal combination of cladding process parameters is current $210 \mathrm{~A}$, pulse width $3.6 \mathrm{~ms}$, frequency $16 \mathrm{~Hz}$, defocusing amount $+10 \mathrm{~mm}$, scanning speed $240 \mathrm{~mm} / \mathrm{min}$. The single pass cladding layer has good surface finish, stable width and height, good bonding between the cladding layer and the substrate, and no cracks, pores and other defects.

Under the comprehensive optimal process parameters, the average hardness of cladding layer, molten pool, heat affected zone and substrate is $406.2 \mathrm{HV}_{0.5}, 470.8 \mathrm{HV}_{0.5}$, $230.5 \mathrm{HV}_{0.5}$ and $202.0 \mathrm{HV}_{0.5}$, respectively. The average micro-hardness of cladding layer is 2.33 times that of 45 steel substrate, and the surface hardness of the substrate after cladding is significantly improved.

Acknowledgements: This work was supported by the National Natural Science Foundation of China (No.51505268),Key project of shaanxi provincial science and technology department (2017ZDXM-GY-138) and Shaanxi provincial education department special research program (16JK1139).

\section{References}

[1] C. Brunner-Schwera, T. Petrata, B. Grafa, et al.. High speed-plasma-laser-cladding of thin wear resistance coatings: A process approach as a hybrid metal deposition-technology [J]. Vacuum, 2019, 166 : 123126.

[2] E Govekar, A Jeromen, A Kuznetsov, et al.. Study of an annular laser beam based axially-fed powder cladding process [J]. CIRP Annals-Manufacturing Technology, 2018, 67: 241-244.

[3] Guo W, Zhang Y P, Chai R X. Numerical Simulation and Experimental Study of Single-Track Laser Cladding of 304 Stainless Steels [J]. Laser \& Optoelectronics Progress, 2019, 56(9): 091401-1-7.

[4] Yu T B, Song B X, Xi W C. Influence of Laser Cladding Process Parameters on Morphology of Cladding Layer and Its Optimization [J]. Journal of Northeastern University (Natural Science), 2019, 40(4): 537-542.

[5] Navas C, Conde A, Fernandez B J, et al.. Laser coatings to improve wear resistance of mouldsteel[J].Surface and Coatings Technology,2005,194(1):136-142.

[6] Huang Y, Sun W L, Chen Y. Trajectory planning of laser cladding remanufacturing for complex shaft shaped part [J].Infrared and Laser Engineering,2017,46(5):0506005.

[7] Wang H, Wang L W , Wang T, et al..Method and implementation of remanufacture and repair of aircraft engine damaged blades[J]. Acta Aeronautica et Astronautica Sinica,2016,37(3): 1036-1048.

[8] Feng H,Li J F,Sun J. Study on Remanufacturing Repair of Damaged Crank Shaft Surface by Laser Cladding [J]. Chinese Journal of Lasers,2014,41(8): 0803003.

[9] Liu F G, Lin X, Song K. Microstructure and Mechanical Properties of Laser Forming Repaired 300M Steel[J]. Acta Metallurgica Sinica,2017,53(3):325-334.

[10] Xu B S, Fang J X, Dong S Y, et al.. Heat-affected Zone Microstructure Evolution And Its Effects On Mechanical Properties For Laser Cladding FV520B Stainless Steel[J]. Acta Metallurgica Sinica, 2016,52(1):1-8.

[11] Song M, Kan Y, Cheng Z H, et al..Study on Microstructure and Performance of Laser Cladding Layer on Ultrahigh Strength Stainless Steel Surface[J].Hot Working Technology, 2017,46(6):148-151+154.

[12] Parekh R, Buddu R K, Patel R I. Multiphysics Simulation of Laser Cladding Process to Study the Effect of Process Parameters on Clad Geometry [J]. Procedia Technology, 2016, 23: 529-536.

[13] Jiao X Y, Wang J, Wang C M, et al..Effect of laser scanning speed on microstructure and wear properties of T15M cladding coating fabricated by laser cladding technology[J]. Optics and Lasers in Engineering,2018,110: 163-171.

[14] Lei J F, Qi W J, Xie Y D, et al..Optimization of Process Parameters of Laser Cladding Ni60-25\%WC Coating on 
U71Mn Steel[J].Surface Technology,2018,47(3):66-70.

[15] Zan S P, Jiao J K, Zhang W W. Study on laser cladding process of $316 \mathrm{~L}$ stainless steel power[J].Laser \& Optoelectronics Progress,2016,6:061406.

[16] Xu M S,Li J F ,Li H D, et al..Influence on Powders and Process Parameters on Bonding Shear Strength in Laser Cladding[J].Journal of Mechanical Engineering,2017,53(9): 209-216.

[17] Xu Q K, Hu J D, Zhang W C. Application of TiBCN Powder as Additive in Laser Cladding of 45 Steel[J]. Applied Laser,2018,38(1):7-11.

[18] Liu X M, Xie J J, Chen H. Manufacturing Stamping Die by Laser Cladding Ni35B+WC on the Surface of 45 Steel [J].
Rare Metal Materials and Engineering,2013,42(2):247-250. [19] Li B C, Zhao Y, Yu T B, et al.. Experimental Study of Single Pass Cladding Layers for Process Parameter Selection of Laser Cladding Ni204 Alloy [J]. Applied Laser,2018, 38(5):713-719.

[20] B Bax, R Rajput, R Kellet, et al.. Systematic evaluation of process parameter maps for laser cladding and directed energy deposition [J]. Additive Manufacturing, 2018, 21: 487-494.

[21] Li Y J, Dong S Y, Yan S X, et al.. Elimination of voids by laser remelting during laser cladding $\mathrm{Ni}$ based alloy on gray cast iron [J]. Optics and Laser Technology, 2019, 112: $30-38$. 